\title{
ROLE OF THE PHARMACIST IN MANAGING HIGH BLOOD PRESSURE OF HYPERTENSIVE PATIENTS IN PRIMARY CARE UNITS
}

\author{
JÚLIO EDUARDO PEREIRA DE SOUZA ${ }^{1,2}$, EMERSON SILVA ${ }^{2}$, NEIL FERREIRA NOVO², MARINA TIEMI SHIO ${ }^{2 *}$ \\ ${ }^{1}$ Associação Saúde da Família - Coordenação Regional Sul - Brazil. ²Post-Graduation Program in Health Sciences, Santo Amaro University, \\ São Paulo, Brazil. Email: mtshio@prof.unisa.br
}

Received: 22 May 2020, Revised and Accepted: 14 September 2020

\section{ABSTRACT}

Objective: The aim of this study was to evaluate the influence of pharmaceutical care on the control of high blood pressure (BP) in hypertensive patients.

Methods: The study included thirty hypertensive patients from primary or secondary healthcare located in the south of São Paulo, Brazil.

Results: The majority of patients was aged over 60 years (68.75\%), non-smokers (90\%), non-alcoholics (93.33\%), did not practice physical activities (93.33\%), and presented comorbidities and Polypharmacoterapy. The most common drug-related problems were drug-drug interactions, missed doses, incorrect frequency or time of administration, incorrect patient administration technique, and self-medication. The interventions used during the pharmaceutical consultations (PC) were based on the organization of medicines with tools such as a pillbox organizer (84.38\%). A significant improvement in BP control $(\mathrm{p}<0.05)$ was observed when comparing BP measurements before and after the PC; however, the number of PCs did not influence the BP reduction.

Conclusion: Patient guidance and a simple intervention favor better patient understanding of medication administration schedules.

Keywords: Pharmaceutical care, Pharmaceutical consultation, Intervention, non-communicable diseases, Hypertension, Polypharmacoterapy.

(C) 2020 The Authors. Published by Innovare Academic Sciences Pvt Ltd. This is an open access article under the CC BY license (http://creativecommons. org/licenses/by/4. 0/) DOI: http://dx.doi.org/10.22159/ajpcr.2020.v13i11.38406

\section{INTRODUCTION}

The Unified Health System (UHS) in Brazil gives great importance to pharmaceutical care [1]. The clinical pharmacist is a professional involved in a multidisciplinary team, which is of paramount importance to obtain adequate pharmacotherapy [2]. In October 2013, a two-step pharmaceutical care plan was implemented in Curitiba - Parana state, Brazil, to create clinical pharmacies with professionals capable of performing appropriate patient care [3].

Brazilian pharmaceutical care has not been developed in a standardized manner, as the policy of each municipality contains a distinct pharmaceutical care model. Therefore, the development of pharmaceutical care depends on the local and current legislation [4-6].

The pharmaceutical care service was established by the Secretary of Municipal Health of São Paulo in the primary healthcare and specialty network, through Ordinance 1918/2016-SMS.G, published in the Official Gazette of the City of São Paulo on October 27, 2016 [7]. The goal was to provide individual and collective therapeutic health outcomes through pharmacist clinical actions, integrated with the multidisciplinary team, promoting the rational use of medicines among prescribers, health teams, and the community, encompassing health education actions, and pharmacovigilance. Pharmacotherapeutic follow-up for UHS users should strengthen adherence to drug treatment, mainly in cases of noncommunicable chronic diseases, which may result in a reduction in hospital admissions in urgency and emergency units [7].

Non-communicable diseases (NCDs) are considered a public health problem worldwide. They have been increasing with the population aging, which changes the epidemiological profile of diseases, reducing infectious diseases, and increasing chronic diseases [8]. NCDs constitute the largest group of diseases in the world, mainly affecting individuals with low income and education, and those with high exposure to risk factors and restricted access to information and health services [9].
The leading causes of these diseases are modifiable risk factors, such as smoking, harmful alcohol consumption, physical inactivity, and improper diet, as well as metabolic risk factors, including hypertension, hyperglycemia, overweight, and dyslipidemia [10].

In Brazil, systemic arterial hypertension (SAH) affects approximately $32.5 \%$ (36 million) of adult individuals, and over $60 \%$ of older adults, contributing directly or indirectly to the percentage of deaths from cardiovascular disease (CVD). The latter is often associated with other chronic diseases and has a major impact on the loss of labor productivity and household income, estimated at $\$ 4.18$ billion between 2006 and 2015. In 2013, there were 1,138,670 deaths, of which 339,672 (28\%) were due to (CVD), this being the leading cause of death in the country for both sexes and all age groups [11]. In the city of São Paulo, the prevalence of SAH reported in the population aged 12 and over corresponded to $14 \%$ (2003), 18.6\% (2008), and 20.2\% (2015) [12].

In 2016, the most common cause of death in Brazil was ischemic heart disease (ICD), followed by stroke. Other causes of death included transmissible diseases (lower respiratory tract infections) and two external causes, aggressions, and land transport accidents, in sixth and eighth place, respectively. All the other causes corresponded to NCDs [13].

From 2005 to 2015, the inadequate therapeutic segment for NCDs in Brazil caused financial losses of approximately $\$ 50$ billion, and premature deaths from CVD and diabetes. The estimated loss in 2005 was $\$ 2.7$ billion and might have reached $\$ 9.3$ billion in 2015. Nonadherence to drug treatment and lack of understanding of treatment by the patient are the main causes of recurrent hospitalizations. Polypharmacotherapy is present in the treatment of NCDs and is defined as the use of five or more drugs, adding difficulty to the process of treatment and adherence [14,15].

Approximately $50 \%$ of patients with chronic diseases do not adhere to pharmacological treatments, resulting in poor clinical outcomes. The 
identification of reasons for drug non-adherence based on a history of unresolved NCDs enables pharmacists to apply interventions, document them, and reschedule pharmaceutical appointments, facilitating the pharmacotherapeutic follow-up. There is sharing of interventions defined in pharmaceutical consultations (PC) for the multidisciplinary team of health units. This organization is required for the patient's perception of health, improving the longitudinal care process. Non-adherence to treatment described in the literature is related to individual patient characteristics, the disease itself, the drugs used, and the interaction between the patient and access to health services, among others. Certain health conditions or treatments may have characteristics that lead to specific barriers to adherence $[16,17]$.

In this line of thought, the evaluation of pharmaceutical assistance in the multiprofessional team would help to establish the fundamental involvement of this professional and his service in primary health care, as well as showing what type of intervention is effective in helping the patient to improve his health condition. Therefore, the aim of this study is evaluate whether PC contributes to a better control of high blood pressure (HBP) in hypertensive patients.

\section{METHODS}

The Research Ethics Committee of the University of Santo Amaro (UNISA) approved the study under protocol number 77408717.5.0000.0081. This retrospective pre- and post-interventional study was conducted in primary and secondary healthcare of the Southern Health Regional Coordination, in the city of São Paulo, Brazil, between March 2017 and December 2019.

Data collection was performed by consulting medical records, medical prescriptions, laboratory records, and reports of PCs applied by pharmaceutical professionals of health units during the process of pharmaceutical care to patients referred by the multidisciplinary team of the units.

\section{Inclusion criteria}

Adult and older patients with NCDs referred to pharmaceutical care by the multidisciplinary team. All of the patients have hypertension and difficulty adhering to drug treatment. Children and adolescents were excluded from this research. Only patients who presented BP measurements during PCs and who were under pharmaceutical care monitoring were selected, totaling 30 patients from 62 consultations, performed by 23 pharmacists, distributed in 38 health units in the south area of São Paulo.

\section{Statistical analysis}

For statistical analyses, we used BioEstat 5.3 software, and the following statistical tests: The Cochran G-Test to compare the frequencies of pharmacotherapy-related problems, comorbidities, and interventions in the form of material provision or referral to other health professionals. Wilcoxon analysis was used to verify whether the number of PCs influenced the reduction in BP and the Fisher's exact test to compare female and male sexes concerning systolic (SBP) or diastolic BP (DBP) before and after PC.

\section{RESULTS}

During the study, the majority of the patients received one $(43.33 \%)$ or two PCs (33.33\%), however, a few patients received six $(6.67 \%)$ or even twelve PCs (3.33\%). Data show the percentage of patients who received one to 12 PCs, taking into account males and females. The majority of patients received one or two PCs during the study period.

Part of the patients referred to PC was female $(56.25 \%)$, as shown in Table 1. Overall patients had more than 60 years old $(68.75 \%)$, as shown in Table 2.

Regarding the modifiable risk factors (Table 3), out of 30 treated patients, only three (10\%) are smokers, two (6.67\%) are alcoholics, and two $(6.67 \%)$ practice regular physical activity. Therefore, the vast majority $(93.33 \%)$ are sedentary.
The most prevalent comorbidities (Table 4) of patients assisted by pharmacists were Type 2 diabetes mellitus, SAH and dyslipidemia (26.67\%), Type 2 diabetes mellitus and SAH (16.67\%), Type 1 diabetes mellitus and SAH (13.33\%), SAH and dyslipidemia (10.00\%), or only SAH $(10.00 \%)$. Due to these comorbidities, a large proportion of the patients were taking more than five drugs (86.67\%), as shown in Table 5 . The most commonly used drug classes are presented in Table 6: Oral hypoglycemic agents (23.19\%), diuretics (12.56\%), antilipemic (11.11\%), angiotensinconverting enzyme inhibitors (9.18\%), platelet anti-aggregants (7.25\%), calcium channel blockers $(6.28 \%)$, beta blockers (5.31\%), proton pump inhibitors (5.31\%), angiotensin receptor blockers (4.83\%), aldosterone antagonist (2.42\%), hormone reposition (2.42\%), antipsychotics, antidepressants, benzodiazepines, and uricosuric agents (1.45\%).

Beyond Polypharmacoterapy, 85 events of Pharmacotherapy-Related Problems were found. The most statistically significant $(\mathrm{p}<0.0001)$ was drug-drug interaction $(n=26)$, followed by missed doses $(n=14)$, incorrect frequency or time of administration, without changing daily dose $(n=13)$, incorrect patient administration technique $(n=9)$, improper self-medication $(n=6)$, drug interruption $(n=6)$, or abrupt dose reduction by the patient $(n=4)$, as shown in Table 7 .

The most commonly used pharmaceutical intervention was the material supply (Table 7), which helped the therapeutic adherence. The most used tool $(\mathrm{p}<0.0000)$ was a pillbox organizer $(84.38 \%)$, followed by pictograms, dosage schedules, and colored stickers. These interventions are simple, and favor a better understanding of the patient regarding medication administration schedules. The tool was widely accepted among patients and it helped their autonomy to use the medication. However, some patients refused to use the tools or it was not necessary $(16.47 \%)$. Another common non-pharmacological intervention is to

Table 1: Gender of patients

\begin{tabular}{lll}
\hline Gender & Number of patients & \% \\
\hline Male & 14 & 46.67 \\
Female & 16 & 53.33 \\
Total & 30 & 100 \\
\hline
\end{tabular}

Table 2: Age range of patients

\begin{tabular}{lll}
\hline Age range (years) & Number of patients & \% \\
\hline $40-49$ & 3 & 10.00 \\
$50-59$ & 6 & 20.00 \\
$60-69$ & 4 & 13.33 \\
$70-79$ & 11 & 36.67 \\
$80-89$ & 6 & 20.00 \\
Total & 30 & 100.00 \\
\hline
\end{tabular}

Table 3: Modifiable risk factors

\begin{tabular}{lllll}
\hline Variables & Yes & No & Total & \% yes \\
\hline Ethylist & 3 & 27 & 30 & 10.00 \\
Smoker & 2 & 28 & 30 & 6.67 \\
Physical activity & 2 & 28 & 30 & 6.67 \\
\hline
\end{tabular}

Table 4: Prevalence of comorbidities

\begin{tabular}{lll}
\hline Comorbidities & Number of patients & \% \\
\hline T2DM/SAH/Dyslipidemia & 8 & 26.67 \\
SAH/T2DM & 5 & 16.67 \\
SAH/T1DM & 4 & 13.33 \\
SAH/Dyslipidemia & 3 & 10.00 \\
SAH & 3 & 10.00 \\
Others & 7 & 23.33 \\
Total & 30 & 100.00 \\
\hline
\end{tabular}

SAH: Systemic arterial hypertension, T1DM: Type 1 diabetes mellitus, T1DM: Type 2 diabetes mellitus 
Table 5: Number of medicines/patients

\begin{tabular}{lll}
\hline Number of medicines & Number of Patients & \% \\
\hline 2 & 1 & 3.33 \\
3 & 1 & 3.33 \\
4 & 2 & 6.67 \\
5 & 6 & 20.00 \\
6 & 6 & 20.00 \\
7 & 4 & 13.33 \\
8 & 3 & 10.00 \\
9 & 2 & 6.67 \\
10 & 2 & 6.67 \\
11 & 1 & 3.33 \\
13 & 1 & 3.33 \\
14 & 1 & 3.33 \\
92 & 30 & 100.00 \\
\hline
\end{tabular}

Table 6: Drugs class of most frequently used medicines

\begin{tabular}{lll}
\hline Class of drugs & Number of patients & \% \\
\hline Oral hypoglycemic agents & 48 & 23.19 \\
Diuretics & 26 & 12.56 \\
Antilipemic & 23 & 11.11 \\
ACE Inhibitors & 19 & 9.18 \\
Platelet antiaggregants & 15 & 7.25 \\
Calcium channel blocker & 13 & 6.28 \\
Beta blockers & 11 & 5.31 \\
Proton pump inhibitors & 11 & 5.31 \\
Angiotensin receptor blocker & 10 & 4.83 \\
Aldosterone antagonist & 5 & 2.42 \\
Hormone reposition & 5 & 2.42 \\
Antiphychotic & 3 & 1.45 \\
Antidepressant & 3 & 1.45 \\
Benzodiazepines & 3 & 1.45 \\
Uricosuric & 3 & 1.45 \\
Others & 9 & 4.35 \\
Total & 207 & 100 \\
\hline ACE Inhibitors: Angiotensin-converting enzyme inhibitors. Some patients used \\
more than one drug from the same drug class
\end{tabular}

Table 7: Prevalence of pharmacotherapy-related problems

\begin{tabular}{lll}
\hline Pharmacotherapy-related problems & $\begin{array}{l}\text { Number of } \\
\text { patients }\end{array}$ & \% \\
\hline Drug-drug interaction & 26 & 30.59 \\
Missed doses & 14 & 16.47 \\
Incorrect frequency & 13 & 15.29 \\
Incorrect technique & 9 & 10.59 \\
Drug interruption & 6 & 7.06 \\
Improper self-medication & 6 & 7.06 \\
Abrupt dose reduction & 4 & 4.71 \\
Others & 7 & 8.24 \\
Total & 85 & 100 \\
\hline
\end{tabular}

refer the patient to other health professionals (Tables 8 and 9), such as nutritionist $(22.22 \%, \mathrm{p}<0.0000)$, physiotherapist, psychologist, occupational therapist, and social worker. Interestingly, $41.7 \%$ of the patients were not referred to other professionals. The latter patients were under care only of the pharmacist professional.

Data show the percentage of the main platelet-rich fibrin (PRF) taking into account male and female gender. The Cochran G-test showed among PRFs, drug-drug interaction is significantly more frequent $\mathrm{G}=93.44(\mathrm{p}<0.0001)$.

Data show that pillbox organizer was the most frequently used tool. Some patients received more than one material $g=71.18(\mathrm{p}=0.0000)$.

Data show the number of patients that did not need or were referred to some healthy professional. Nutritionists were significantly more indicated compared to others. Some patients were referred to more than one healthy professional $g=68.8(\mathrm{p}=0.0000)$.

To analyze whether PC helps to control patients' BP with hypertension, SBP, or DBP, BP was assessed before or during the first consultation, after the intervention or at the last appointment. Delta was calculated for SBP and DBP $(\triangleq[$ (PAS before - PAS after $) \div$ PAS before $] \times 100)$. Then, Wilcoxon analysis was performed to verify if the number of PCs was related to BP reduction and no statistical difference was observed (SBP, $p=0.3844$ and DBP, $p=0.5727$ ), data not shown. Subsequently, the difference between SBP before and after PC was analyzed and a statistically significant reduction was detected $(\mathrm{p}=0.0006)$. Concerning $\mathrm{DBP}$, no statistical difference was observed with this sample size ( $\mathrm{p}=0.1285)$ (Fig. 1).

We analyzed whether the difference in SBP occurred more in men or women, and we observed that the difference remained (male $p=0.0075$ and female $p=0.0356$ ) (Fig. 2).

Next, we evaluated whether gender influences the BP reduction, and we observed that men presented higher SBP before PC compared to women ( $p=0.0421$ ) (Fig. 3). Finally, no differences between DBP before and after PC were observed in men and women $(p=0.1239, p=0.0742$ and $\mathrm{p}=0.5688$, respectively, data not shown).

\section{DISCUSSION}

The present study showed the results of pharmaceutical care 2 years after its introduction as a normative service in the city of São Paulo, Brazil. The systolic BP of thirty hypertensive patients of 60 years or over, predominantly not alcoholics or smokers, sedentary, and significantly reduced after PC.

Unfortunately, the data of some independent variables were missing, such as ethnicity/color, height, educational level, as well as weight, body mass index, and waist circumference. These information could be important, as being overweight accounts for the burden of many NCDs [8]. The lack of some data in medical records for longitudinal follow-up of patients demonstrates the need for improvement in the use of this fundamental instrument by the multidisciplinary team. Pharmacists could complement some missing data, as most consultations were performed at home visits, and the forms completed by pharmacists include pharmaceutical history, investigation of medication used, and analysis of patient's clinical history. However, in the current study, the pharmacists did not obtain data such as education, ethnicity, color, and circumferences at the consultations performed at the patients' homes. One method that might be helpful is the subjective, objective, assessment, and plan note, which helps healthcare workers to organize patient documentation [18]. This instrument could be used to train future pharmacists to provide uniform documentation [19].

Table 8: Intervention with material provision

\begin{tabular}{lll}
\hline Materials & Number of patients & $\mathbf{\%}$ \\
\hline Pillbox organizers & 25 & 84.38 \\
No Need/Denied use & 5 & 16.47 \\
Pictograms & 3 & 9.38 \\
Dosage schedules & 1 & 3.13 \\
Colored Sticker & 1 & 3.13 \\
Total & 35 & 100 \\
\hline
\end{tabular}

Table 9: Intervention referring to others professionals

\begin{tabular}{lll}
\hline Professionals & Number of patients & $\mathbf{\%}$ \\
\hline Nutritionist & 8 & 22.22 \\
Physiotherapist & 3 & 8.33 \\
Psychologist & 2 & 5.56 \\
Occupational therapist & 2 & 5.56 \\
Social Worker & 2 & 5.56 \\
Others & 4 & 18.76 \\
No need & 15 & 41.70 \\
Total & 36 & 100 \\
\hline
\end{tabular}




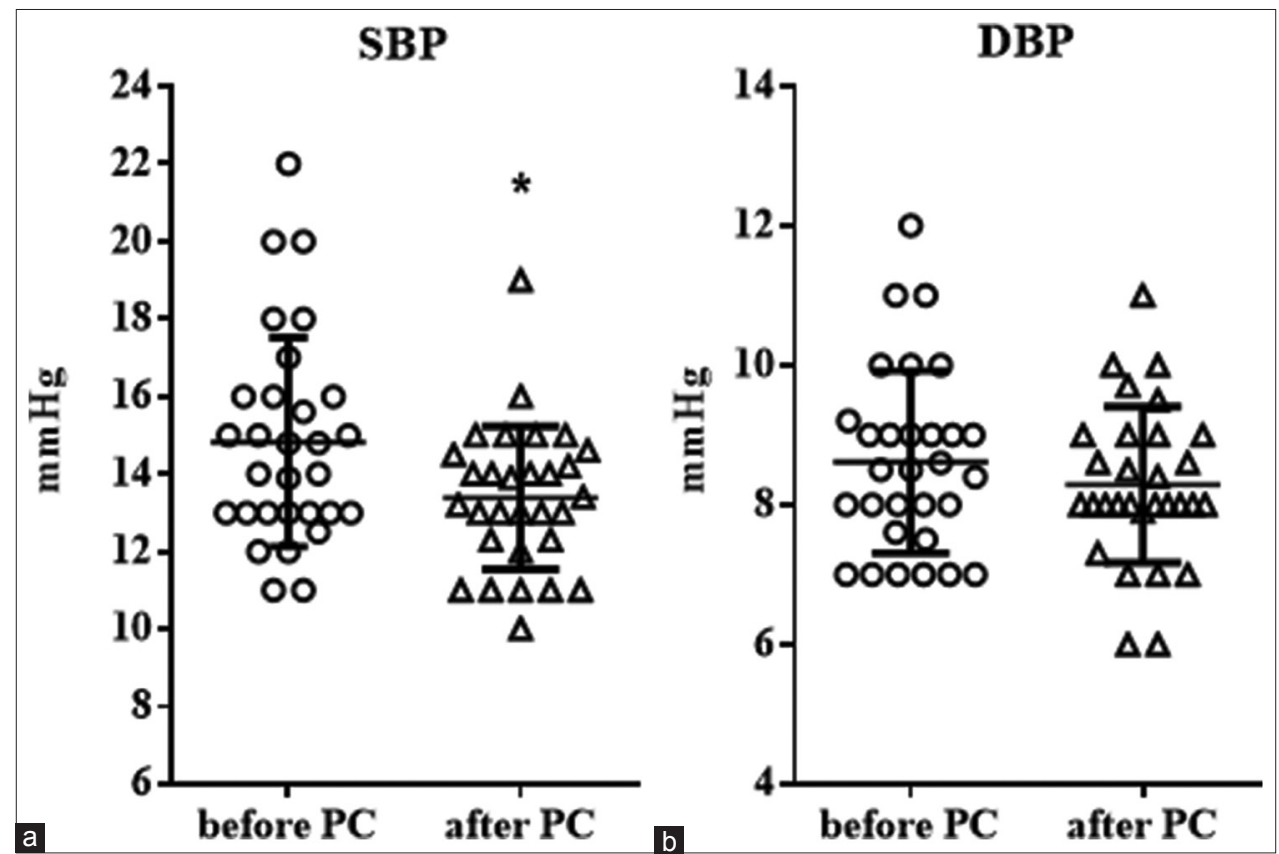

Fig. 1: (a and b) Systolic blood pressure (SBP) and diastolic blood pressure (DBP), blood pressure measurements before and after pharmaceutical consultation (PC). Data show mean \pm SEM of SBP and DBP measurements before and after PC taking into account males and females. $\mathrm{n}=30, \mathrm{SBP} * \mathrm{p}=0.0006$, and $\mathrm{DBP} \mathrm{p}=0.1285$

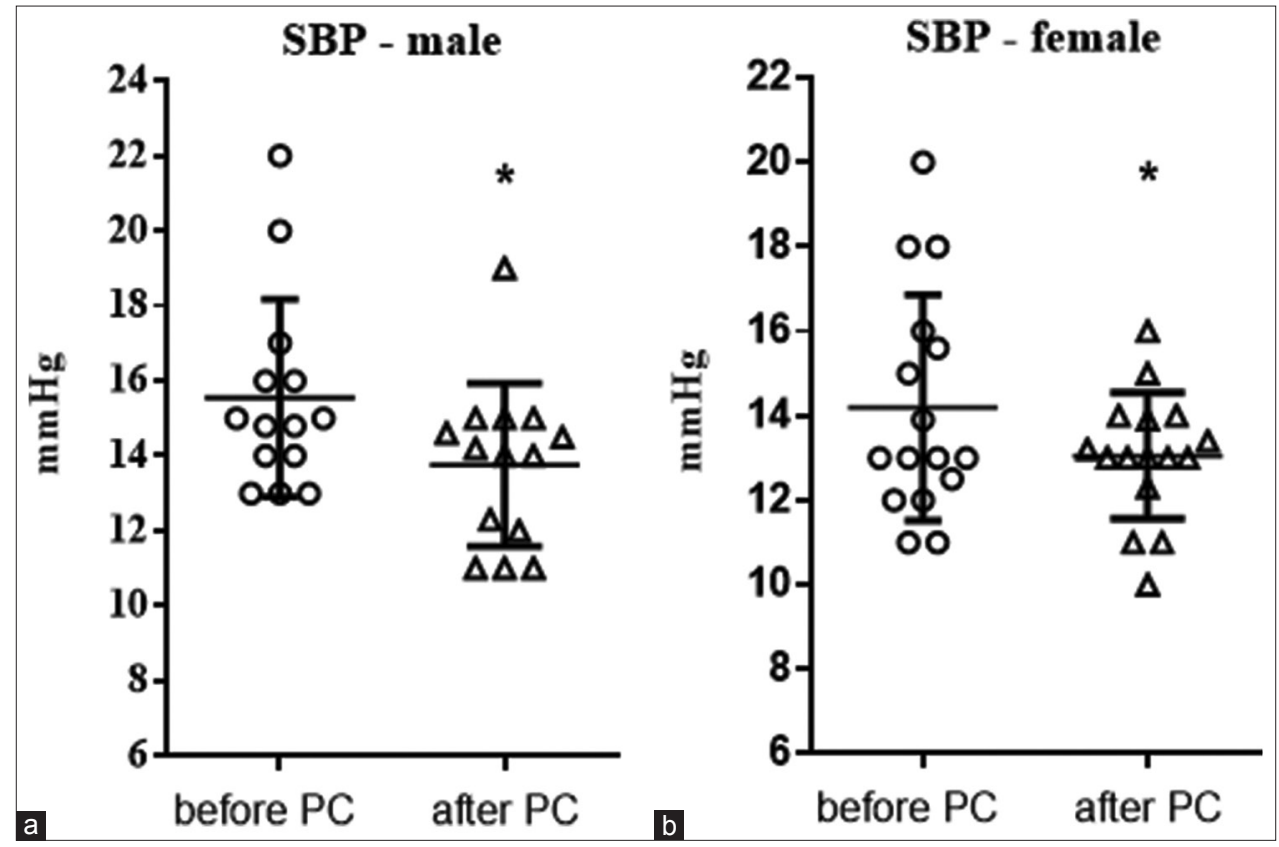

Fig. 2: Systolic blood pressure (SBP) measurements before and after pharmaceutical consultation (PC). Data show mean \pm SEM of SBP measurements before and after PC, separated by males $(a, n=14)$ and females $(b, n=16) . S B P * p=0.0075$ and $D B P * p=0.0356$

Regarding the modifiable risk factors, the data of the present study showed the same worldwide trend as for physical inactivity. According to the World Trends Survey in insufficient physical activity, from 2001 to 2016 , one in three women $(32 \%)$ and one in four men $(23 \%)$ did not reach the recommended levels of physical activity to stay healthy (at least $150 \mathrm{~min}$ of moderate intensity or $75 \mathrm{~min}$ of vigorous intensity per week) [20]. In São Paulo, according to data obtained in 2017 by Vigitel health (a supplemental report of a risk factor surveillance system for NCDs of the Ministry of Health, concerning physical activity), the percentage of physically active individuals is $34.8 \%, 42.4 \%$ (male), and $28.7 \%$ (female) [21]. These numbers are higher than those found in the present study, in which only $6.67 \%$ of patients perform physical activity.
The number of individuals that smoke or consume alcohol was very similar to the present study, according to Vigitel, 2017, the percentage of adult smokers corresponds to $10.3 \%$ of the population, being $11.8 \%$ (male), and $9.1 \%$ (female). Regarding consumption of alcoholic beverages, the report shows that the percentage of alcoholic adults in the state of São Paulo is $16.7 \%, 22.1 \%$ (male), and $12.5 \%$ (female) [22].

Besides modifiable behavioral risk factors, some metabolic risk factors were observed during the PCs, the most common of which were hypertension, hyperglycemia, and dyslipidemia. The presence of comorbidity increases the number of prescribed drugs. In the present study, we observed that $85 \%$ of the patients take more than five 


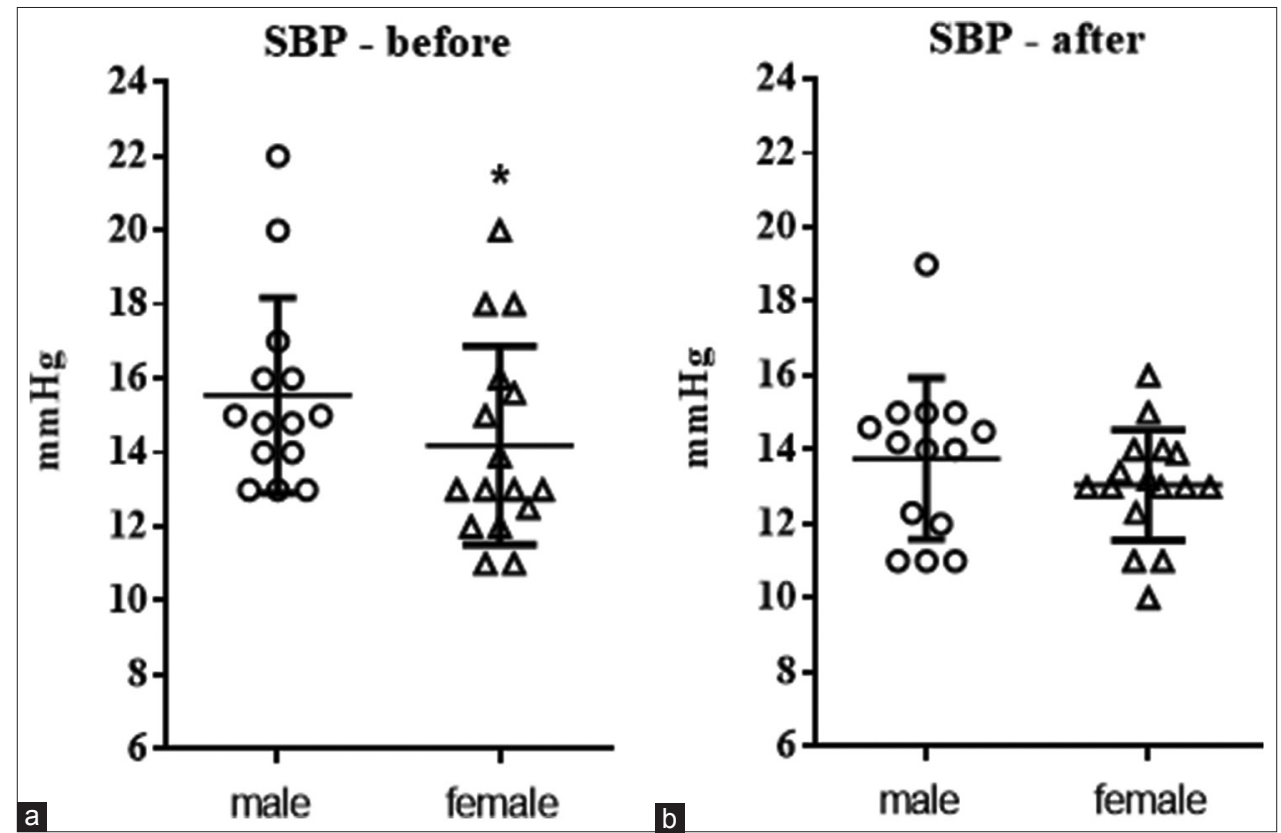

Fig. 3: Systolic blood pressure (SBP) measurements of men and women, before and after pharmaceutical consultation (PC). Data show mean \pm SEM of SBP measurements before (a) and after (b) PC, comparing male $(n=14)$ and female $(n=16)$ genders. SBP-before * $p=0.0421$

medications, and the majority of the drug classes are associated with patient comorbidities, with polypharmacy already a reported issue in patients of the UHS [16]. Similar results were obtained in other studies in which the most commonly used antihypertensive classes being Thiazide diuretics (28.44\%), followed by angiotensin-converting enzyme inhibitors (27.49\%) and Beta-blockers (20.55\%) [23,24]. The most widely used drugs are among those recommended as first-line drugs for the control of arterial hypertension. The proportion of people using more than one drug seems to follow the behavior observed in other countries $[16,25]$. The maintenance of a free supply of antihypertensive drugs is very important for advancing the control of SAH. However, complementary actions are required to ensure adherence to the prescribed medication, the continuous care of the people treated, and the promotion of healthy habits [26]. In addition, improvements in population education and income may substantially contribute to SAH control [27].

Complex medication schemes related to polypharmacotherapy lead to non-adherence [28]. The number of drugs proved to be a stronger predictor of non-adherence than advanced age, with higher rates of non-adherence as the number of drugs increased. Non-adherence can lead to serious sequelae including disease progression, treatment failure, hospitalization, and adverse events $[16,29]$.

Concerning drug-related problems, 85 were found in the present study, with drug-drug interactions being the most frequent, followed by missed doses and incorrect frequency or time of administration without changing daily dose. Drug-related problems seem to differ according to region and country [30-35].

The number of consultations carried out by pharmacists is associated with patients with greater difficulty in adhering to drug treatment and/or SBP control. Herein, during the period of the study, most of the patients had one or two PCs; however, some patients had up to 12 PCs. With the implementation of Pharmaceutical Care in Primary Health Care in Curitiba - Brazil, in April 2014, a gradual increase was observed in the number of consultations during the $1^{\text {st }}$ year of implementation [36].

During PC, some of the interventions applied, such as patient guidance and supply of helpful materials, aided patients in understanding the schedule of medicine administration. Pillboxes are known to improve medication adherence $[37,38]$. However, taking the drugs out of the original container can compromise their stability and safeness [39]. Some of the patients were referred to other health-care professionals, mainly nutritionists. This professional is important for the management of overweight and obesity in adults [40].

A significant reduction in SBP was observed after PC, independently of the number of PCs. In agreement with this result, a systematic review showed that a reduction in SPB was the main outcome observed after pharmaceutical intervention in North America [41]. A study conducted in the city of Ribeirão Preto, Brazil, demonstrated that $54 \%$ of patients presented satisfactory SBP, and after PCs, this number increased to $95 \%$ [42]. A prospective clinical trial with a total of 194 patients evaluated the impact of pharmaceutical care in diabetic and/or hypertensive patients. The intervention group under pharmaceutical care demonstrated significant control of SBP and DBP, as well as glycemia, dyslipidemia, body mass index, and abdominal circumference [43]. In addition to pharmaceutical care, the Brazilian Longitudinal Study of Aging (ELSI-Brazil) showed that BP control is associated with education level, socio-economic status, a private health plan, and obesity [27]. Thus, pharmacist intervention is important to provide education of patient and to improve medication adherence of hypertensive and heart failure patients [44-46].

\section{CONCLUSION}

Overall, to establish effective performance in Primary Health Care and Specialized Care, the pharmacist must work and be inserted in healthcare teams, as already occurs with other professionals, to avoid fragmented and isolated work. Finally, to develop future research, investigations should be carried out in other health units in São Paulo, and the data collected in this study should be followed up.

\section{AUTHORS' CONTRIBUTIONS}

JEPS: Collected and organized the data; wrote the manuscript.

ES: Collected and organized the data.

NFN: Made statistical analysis.

MTS: Organized the data, wrote, and submitted the manuscript.

\section{DECLARATION OF CONFLICTING INTERESTS}

The author(s) declare no conflicts of interest regarding the research, authorship, or publication of the present work. 


\section{FUNDING}

The fellowship program of the Family Health Association and UNISA supported J.E.P.S.

\section{ETHICAL APPROVAL}

The Research Ethics Committee of the University Santo Amaro (UNISA) approved the present study, protocol No. 3.073.126 and CAAE 77408717.5.0000.0081.

\section{REFERENCES}

1. Costa KS, Tavares NU, Nascimento JM, Mengue SS, Alvares J, Guerra AA, et al. Pharmaceutical services in the primary health care of the Brazilian unified health system: Advances and challenges. Rev Saude Publica 2017;51:3S

2. Strand LM, Guerrero RM, Nickman NA, Morley PC. Integrated patientspecific model of pharmacy practice. Am J Hosp Pharm 1990;47:550-4.

3. Ministério da Saude. Diário Oficial da União Brasil: Diário Oficial da União Brasil. Lei No. 8.080. Brazil: Ministério da Saude; 1990.

4. Araújo AL, de Freitas O. Conceptions of the pharmaceutical professional about the pharmaceutical assistance in basic health care units: Difficulties and elements for change. Rev Bras Cienc Farm 2006;42:134-46.

5. Fegadolli C, Cavaco AM, Fonseca DC. Revisiting concepts, attitudes and expectations of Brazilian pharmacists to the practice of pharmaceutical care: A qualitative perspective. Indian J Pharm Educ Res 2018:52:1-9.

6. Silva BB, Fegadolli C. Implementation of pharmaceutical care for older adults in the Brazilian public health system: A case study and realistic evaluation. BMC Health Serv Res 2020;20:37-51

7. Que Institui Os Cuidados Farmacêuticos No Âmbito da Secretaria Municipal de Saúde do Município de São Paulo 1918/2016-SMS.G, Portaria No. 1.918/2016-SMS.G; 2016.

8. Saklayen MG. The global epidemic of the metabolic syndrome. Curr Hypertens Rep 2018;20:12-20.

9. GBD 2015 Risk Factors Collaborators. Global, regional, and national comparative risk assessment of 79 behavioural, environmental and occupational, and metabolic risks or clusters of risks, 1990-2015: A systematic analysis for the global burden of disease study 2015. Lancet 2016;388:1659-724

10. World Health Organization. Noncommunicable Diseases Country Profiles 2018. Geneva: World Health Organization; 2018.

11. Plavnik FL, Machado CA, Malta D, Scala LC, Fuchs S. $7^{\text {th }}$ Brazilian guideline of arterial hypertension. Braz J Hypertens 2017;24:12-6.

12. Ministério da Saúde. Relatório Anual de Gestão-2018; 2018. Available from: https://www.prefeitura.sp.gov.br/cidade/secretarias/upload/ saude/relatorio anual gestao 2018.pdf. 2018.

13. Ministério da Saúde. In: Ministério da Saúde SdVeS, Departamento de Vigilância de Doenças e Agravos Não Transmissíveis e Promoção da Saúde, editors. Health Brazil 2018: An Analysis of the Health Situation and of Chronic Diseases and Conditions: Challenges and Perspectives. Brasília: Ministério da Saúde; 2019. p. 414.

14. Mendes EV. Health care networks. Cien Saude Colet 2010;15:2297-305.

15. Menicucci TM. The unified national health system, 20 years: Assessment and perspectives. Cad Saude Publica 2009;25:1620-5.

16. Nascimento RC, Álvares J, Guerra AA Jr., Gomes IC, Silveira MR, Costa EA, et al. Polypharmacy: A challenge for the primary health care of the Brazilian unified health system. Rev Saude Publica 2017;51:19S.

17. Porter ME, Teisberg EO. Redefining Health Care: Creating ValueBased Competition on Results. Massachusetts, Boston: Harvard Business School Press; 2006

18. Gossman W, Lew V, Ghassemzadeh S. SOAP notes. In: Stat Pearls. Treasure Island, FL: Stat Pearls Publishing; 2020

19. Sando KR, Skoy E, Bradley C, Frenzel J, Kirwin J, Urteaga E. Assessment of SOAP note evaluation tools in colleges and schools of pharmacy. Curr Pharm Teach Learn 2017;9:576-84.

20. Guthold R, Stevens GA, Riley LM, Bull FC. Worldwide trends in insufficient physical activity from 2001 to 2016: A pooled analysis of 358 population-based surveys with 1.9 million participants. Lancet Glob Health 2018;6:e1077-86.

21. Malta DC, Silva M, Moura L, Morais OL. The implantation of the surveillance system for non-communicable diseases in Brazil, 2003 to 2015: Successes and challenges. Braz J Epidemiol 2017;20:661-75.

22. Malta DC, Bernal RT, Andrade S, Silva M, Velasquez-Melendez G. Prevalence of and factors associated with self-reported high blood pressure in Brazilian adults. Rev Saude Publica 2017;51:11S.
23. Morgado MP, Rolo SA, Pereira L, Castelo-Branco M. Blood pressure control and antihypertensive pharmacotherapy patterns in a hypertensive population of Eastern Central Region of Portugal. BMC Health Serv Res 2010;10:349.

24. Mengue SS, Bertoldi AD, Ramos LR, Farias MR, Oliveira MA, Tavares NU, et al. Access to and use of high blood pressure medications in Brazil. Rev Saude Publica 2016;50:8S

25. Soler O, Barreto JO. Community-level pharmaceutical interventions to reduce the risks of polypharmacy in the elderly: Overview of systematic reviews and economic evaluations. Front Pharmacol 2019;10:302S

26. Facchini LA, Tomasi E, Dilélio AS. Quality of primary health care in Brazil: Advances, challenges and perspectives. Saúde Debate 2018;42:208-23

27. Firmo JO, Mambrini JV, Peixoto SV, Loyola-Filho AI, Souza PR Jr., Andrade FB, et al. Adequate control of hypertension among older adults: ELSI-Brazil. Rev Saude Publica 2018;52 Suppl 2:13S.

28. Tavares NU, Bertoldi AD, Mengue SS, Arrais PS, Luiza VL, Oliveira MA et al. Factors associated with low adherence to medicine treatment for chronic diseases in Brazil. Rev Saude Publica 2016;50:10S.

29. Shah BM, Hajjar ER. Polypharmacy, adverse drug reactions, and geriatric syndromes. Clin Geriatr Med 2012;28:173-86.

30. Huri HZ, Wee HF. Drug related problems in Type 2 diabetes patients with hypertension: A cross-sectional retrospective study. BMC Endocr Disord 2013;13:2

31. Yimama M, Jarso H, Desse TA. Determinants of drug-related problems among ambulatory Type 2 diabetes patients with hypertension comorbidity in Southwest Ethiopia: A prospective cross sectional study. BMC Res Notes 2018;11:679-85.

32. Nascimento YA, Carvalho WS, Acurcio FA. Drug-related problems observed in a pharmaceutical care service, Belo Horizonte, Brazil. Braz J Pharm Sci 2009;45:321-30.

33. Kovacevic SV, Miljkovic B, Culafic M, Kovacevic M, Golubovic B, Jovanovic $\mathrm{M}$, et al. Evaluation of drug-related problems in older polypharmacy primary care patients. J Eval Clin Pract 2017;23:860-5.

34. Al-Azzam SI, Alzoubi KH, AbuRuz S, Alefan Q. Drug-related problems in a sample of outpatients with chronic diseases: A cross-sectional study from Jordan. Ther Clin Risk Manag 2016;12:233-9.

35. Farha RA, Basheti I, Al Ruz HA, Alsaleh A, AbuRuz S. Assessment of drug-related problems and their impact on blood pressure control in patients with hypertension. Eur J Hosp Pharm 2016;23:126-30.

36. Ministério da Saúde. In: Ministério da Saúde SDC, Tecnologia e Insumos Estratégicos, Departamento de Assistência Farmacêutica e Insumos Estratégicos, editor. Secretaria de Ciência. Resultados do Projeto de Implantação do Cuidado Farmacêutico no Município de Curitiba. Brasília: Ministério da Saúde; 2015. p. 100

37. Conn VS, Ruppar TM, Chan KC, Dunbar-Jacob J, Pepper GA, de Geest $\mathrm{S}$. Packaging interventions to increase medication adherence: Systematic review and meta-analysis. Curr Med Res Opin 2015;31:145-60.

38. Wali H, Hudani Z, Wali S, Mercer K, Grindrod K. A systematic review of interventions to improve medication information for low health literate populations. Res Social Adm Pharm 2016;12:830-64.

39. Borja-Oliveira CR. Pill organizers and pill cutters: Risks and limitations. Rev Saude Publica 2013;47:123-7.

40. Howatson A, Wall CR, Turner-Benny P. The contribution of dietitians to the primary health care workforce. J Prim Health Care 2015;7:324-32.

41. Aguiar PM, Balisa-Rocha BJ, Brito GC, da Silva WB, Machado M, Lyra DP Jr., Pharmaceutical care in hypertensive patients: A systematic literature review. Res Social Adm Pharm 2012;8:383-96.

42. Cazarim MS, de Freitas O, Penaforte TR, Achcar A, Pereira LR. Impact assessment of pharmaceutical care in the management of hypertension and coronary risk factors after discharge. PLoS One 2016;11:e 0155204.

43. Obreli-Neto PR, Marusic S, Guidoni CM, Baldoni AO, Renovato RD, Pilger D, et al. Economic evaluation of a pharmaceutical care program for elderly diabetic and hypertensive patients in primary health care: A 36-month randomized controlled clinical trial. J Manag Care Spec Pharm 2015;21:66-75.

44. Kandasamy K, Natarajan A, Sebastian J, Konakalla M, Sam R, Rajagopal SS, et al. Impact of pharmacist intervention in screening and education on blood pressure in a rural area in Southern India. Asian J Pharm Clin Res 2016;9:339-43

45. Andhuvan G, Venkatachalam VV, Sankar V. Impact of pharmacist education on medication adherance in heart failure patients. Int J Pharm Sci Res 2014;6:474-6.

46. Thomas JA, Snigdha KS, Karanath PM, Swaroop AM. Impact of patient counselling on knowledge, attitude, and practice of hypertensive patients in a tertiary care hospital. Int J Pharm Sci Res 2017;9:122-5. 